\title{
Effects of Hole-Collecting Buffer Layers and Electrodes on the Performance of Flexible Plastic Organic Photovoltaics
}

\author{
Sungho Woo, ${ }^{1}$ Hong-Kun Lyu, ${ }^{1}$ Yoon Soo Han, ${ }^{2}$ and Youngkyoo $\mathrm{Kim}^{3}$ \\ ${ }^{1}$ Green Energy Research Division, Daegu Gyeongbuk Institute of Science and Technology (DGIST), Daegu 711-873, Republic of Korea \\ ${ }^{2}$ Department of Advanced Energy Material Science and Engineering, Catholic University of Daegu, \\ Gyeongbuk 712-702, Republic of Korea \\ ${ }^{3}$ Organic Nanoelectronics Laboratory, Department of Chemical Engineering, Kyungpook National University, \\ Daegu 702-701, Republic of Korea
}

Correspondence should be addressed to Sungho Woo; shwoo@dgist.ac.kr and Youngkyoo Kim; ykimm@knu.ac.kr

Received 11 June 2013; Accepted 8 July 2013

Academic Editor: Stefano Caramori

Copyright (C) 2013 Sungho Woo et al. This is an open access article distributed under the Creative Commons Attribution License, which permits unrestricted use, distribution, and reproduction in any medium, provided the original work is properly cited.

\begin{abstract}
Here we report the influences of the sheet resistance $\left(R_{\text {sheet }}\right)$ of a hole-collecting electrode (indium tin oxide, ITO) and the conductivity of a hole-collecting buffer layer (poly(3,4-ethylenedioxythiophene):poly(styrenesulfonate), PEDOT:PSS) on the device performance of flexible plastic organic photovoltaic (OPV) devices. The series resistance $\left(R_{S}\right)$ of OPV devices steeply increases with increasing $R_{\text {sheet }}$ of the ITO electrode, which leads to a significant decrease of short-circuit current density $\left(J_{\mathrm{SC}}\right)$ and fill factor (FF) and power conversion efficiency, while the open-circuit voltage $\left(V_{\mathrm{OC}}\right)$ was almost constant. By applying high-conductivity PEDOT:PSS, the efficiency of OPV devices with high $R_{\text {sheet }}$ values of $160 \Omega / \square$ and $510 \Omega / \square$ is greatly improved, by a factor of 3.5 and 6.5 , respectively. These results indicate that the conductivities of ITO and PEDOT:PSS will become more important to consider for manufacturing large-area flexible plastic OPV modules.
\end{abstract}

\section{Introduction}

Organic photovoltaic (OPV) devices have attracted considerable attention as a promising solution for next-generation solar energy conversion, due to their potential to realize low-cost, flexible, large-area, and simple solution processed photovoltaics $[1,2]$. The power conversion efficiency (PCE) of OPVs has been greatly improved by introducing donoracceptor bulk hetero junction (BHJ) structures, with a PCE of about $5 \%$ being achieved for a single junction cell based on blend systems of poly(3-hexylthiophene) (P3HT) and $[6,6]$-phenyl- $\mathrm{C}_{61}$-butyric acid methyl ester (PCBM) [3-5]. There is still further potential to increase the PCE to above $10 \%$ by using low band gap materials and/or tandem cell structures $[1,6,7]$. To date, however, most studies have focused on performance improvement based on an indiumtin-oxide- (ITO-) coated rigid glass substrate so that the advantages of organic-based photovoltaic devices have not been fully exploited. A plastic substrate with an ITO electrode is considered the best candidate to achieve a fully flexible
OPV [8]. To increase the transparency and conductivity of an ITO thin film, it is necessary to heat the substrate at $200 \sim 300^{\circ} \mathrm{C}$ to enhance the ITO crystallization as well as to facilitate diffusion and substitution of tin ions during the ITO deposition process. With a plastic substrate, however, heating beyond that temperature is difficult due to its poor thermal stability, and thus the conductivity of ITO becomes lower than that of glass-based substrates. Probable limiting factor of the PCE for flexible plastic substrate-based OPVs relative to OPVs based on glass substrates are the low conductivity of the ITO electrode and the temperature limitation of the postthermal annealing process of the photoactive layer due to the weak thermal properties of plastic substrates.

Kang et al. reported that reducing $R_{\text {sheet }}$ of the ITO electrode led to enhanced device performance by decreasing the $R_{S}$ value of OPV devices [9]. Therefore, it is imperative to mitigate the high $R_{\text {sheet }}$ (or bulk resistance) problem of ITO electrodes in flexible plastic substrate-based OPVs and/or large-area OPV module products. In case of using the same photoactive material and cathode electrode, the conductivity 
of the hole-collecting buffer layer (HCBL) is another factor related to the $R_{S}$ of OPV devices. The most commonly used HCBL material for OPVs is PEDOT:PSS, which plays an important role in organic electronics such as controlling the hole transport conditions, reducing surface roughness of the substrate, and converting nonohmic contacts into ohmic states. Representative commercially available PEDOT:PSS include CLEVIOS P VP AI 4083 (AI4083) and CLEVIOS PH 500 (PH500), with conductivity of $10^{-3} \mathrm{~S} \mathrm{~cm}^{-1}$ and $10 \sim 50 \mathrm{~S} \mathrm{~cm}^{-1}$, respectively $[10,11]$. It is well known that a highly conductive PEDOT:PSS would be helpful to enhance PCE by providing fast charge transfer with small resistance as well as improved surface or interface properties. Ko et al. [12] and $\mathrm{Hu}$ et al. reported that improved device performance could be attributed to the reduction of the resistance of PEDOT:PSS by doping organic solvents [13]. Xiao et al. [14] and Sun et al. suggested that enhanced performance can also be achieved through an increase of light absorption in the active layer by improving light scattering and by obtaining high surface area with solvent-treated PEDOT:PSS [15]. Lastly, improvement of interfacial properties and alignment of surface free energy between PEDOT:PSS and the active layer could be another factor to facilitate greater device performance [16-18]. However, the aforementioned experiments were mostly performed on glass-based low $R_{\text {sheet }}$ ITO electrodes $(\sim 10 \Omega / \square)$. Therefore, the influence of the PEDOT:PSS conductivity on the performance of OPVs with a high $R_{\text {sheet }}$ ITO electrode warrants further study for understanding delicate changes in final solar module performances when flexible plastic OPV devices are commercialized.

In this work, we investigated the effect of $R_{\text {sheet }}$ of ITO electrode on the performance of OPV devices and also assessed whether the high $R_{\text {sheet }}$ of an ITO electrode on a flexible substrate could be compensated by using highconductivity PEDOT:PSS in the normal configuration of flexible substrate/ITO/PEDOT:PSS/P3HT:PCBM/LiF/Al. Our results show that the conductivity of ITO and PEDOT:PSS strongly affects devices parameters including short-circuit current density $\left(J_{\mathrm{SC}}\right)$, fill factor $(\mathrm{FF})$, and PCE through their influence on the device $R_{S}$.

\section{Experimental}

2.1. Materials and Device Fabrication. To investigate the influence of ITO and PEDOT:PSS conductivity on the device efficiency, we fabricated a total of 8 devices using four types of substrates, glass/ITO ( $6 \Omega / \square$, from SUNIC System Ltd., Republic of Korea), poly(ethylene naphthalate) $(\mathrm{PEN}) / \mathrm{ITO}(21 \Omega / \square$, from Peccell Co., Japan), poly(ether sulfone) (PES)/ITO (160 $\Omega / \square$, from I-component Co., Republic of Korea), and poly(ethylene terephthalate) (PET)/ITO ( $510 \Omega / \square$, from Toray Industries Inc., Japan), with two types of PEDOT:PSS buffer layers, AI4083 and PH500 (modified with 5\% DMSO in our laboratory), from Heraeus Precious Metals $\mathrm{GmbH} \& \mathrm{Co}$. KG.

The OPV devices were fabricated as follows: the patterned ITO substrates were sequentially cleaned by ultrasonic treatment in methanol, de-ionized water, and isopropyl alcohol and dried in a vacuum oven. After being treated with $\mathrm{UV}-\mathrm{O}_{3}$ for $15 \mathrm{~min}$, PEDOT:PSS was immediately spin-coated on the ITO substrate. The coated PEDOT:PSS films were baked on a hot plate for $15 \mathrm{~min}$ at $120^{\circ} \mathrm{C}$ to give a thickness of $30 \mathrm{~nm}$ and transferred to a glove box filled with $\mathrm{N}_{2}$ gas for the remaining fabrication steps. P3HT and PCBM with weight ratios of 1: 0.9 were dissolved in chlorobenzene, followed by stirring for $24 \mathrm{~h}$ at $50^{\circ} \mathrm{C}$. An active layer consisting of P3HT:PCBM blends was spin-cast on top of the PEDOT:PSS layer and dried on a hot plate for $40 \mathrm{~min}$ at $50^{\circ} \mathrm{C}$ to give a thickness of $120 \mathrm{~nm}$. A top electrode consisting of a $\operatorname{LiF}(1 \mathrm{~nm})$ layer and a subsequent $\mathrm{Al}(100 \mathrm{~nm})$ layer were deposited by thermal evaporation under a vacuum of $\sim 10^{-7}$ Torr. The deposited $\mathrm{Al}$ electrode defines an active area of the device as $0.09 \mathrm{~cm}^{2}$. The prepared devices were directly annealed on a hot plate for $15 \mathrm{~min}$ at $120^{\circ} \mathrm{C}$. Although the device annealing process is generally performed at $140^{\circ} \mathrm{C} \sim 150^{\circ} \mathrm{C}$ for glass-based OPVs in order to develop well-ordered active layer morphology and enhance the device efficiency, we conducted the annealing process for all devices including a glass/ITO reference at $120^{\circ} \mathrm{C}$ because of device failure of our plastic/ITO-based OPV devices annealed at temperature over $130^{\circ} \mathrm{C}$.

2.2. Measurements. The conductivity of the ITO electrode was measured in a unit of $\Omega / \square\left(R_{\text {sheet }}\right)$ by the 4-point probe method (CMT-series, Advanced Instrument Technology) [19], and the transmittance was measured with a UVVis spectrometer (Lambda 750, PerkinElmer). Photocurrent density-voltage $(J-V)$ measurements were performed with a Keithley model 2400 Source Meter and a Newport 91192 solar simulator system (equipped with a $1 \mathrm{KW}$ xenon arc lamp, Oriel). Light intensity was adjusted to simulated AM1.5 radiation at $100 \mathrm{~mW} / \mathrm{cm}^{2}$ with a Radiant Power Energy Meter (model 70260, Oriel). The $R_{S}$ value of OPV was calculated from the inverse slope of the $J-V$ curve at high cell voltages $(J=0)$. All measurements were carried out under ambient conditions at room temperature.

\section{Results and Discussion}

To compare the performance of OPVs according to the conductivity of the ITO electrode and the PEDOT:PSS buffer layer, we fabricated several identically structured devices, but with different substrates of glass/ITO $(6 \Omega / \square)$, PEN/ITO (21 $\Omega / \square)$, PES/ITO (160 $\Omega / \square)$, and PET/ITO $(510 \Omega / \square)$ and also with different PEDOT:PSS of AI4083, PH500, as shown in Figure 1 (note the chemical structures of plastic substrates just below the device structures in Figure 1(b)). The conductivities of two different PEDOT:PSS samples are also given in this figure. As shown in Figure 1(c), the OPV devices fabricated with the plastic substrates were bendable and flexible even in small sizes compared to that fabricated with glass substrate.

The optical transmittance spectra of ITO-coated glass and three different ITO-coated plastic substrates are given in Figure 2. The transmittance at the wavelength between $450 \mathrm{~nm}$ and $550 \mathrm{~nm}$ was slightly lower for the plastic substrates than the glass substrate, whereas it was reversed 


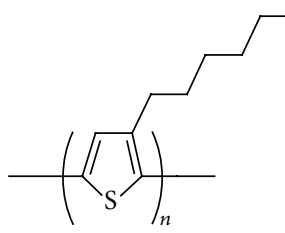

P3HT
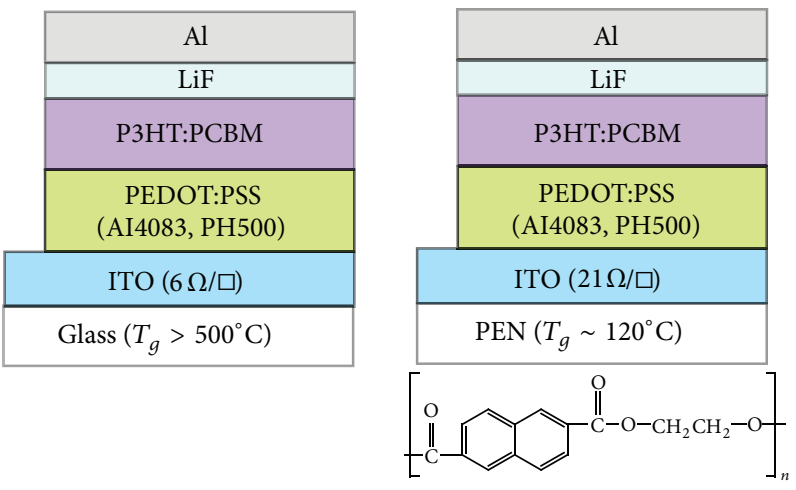

PEN
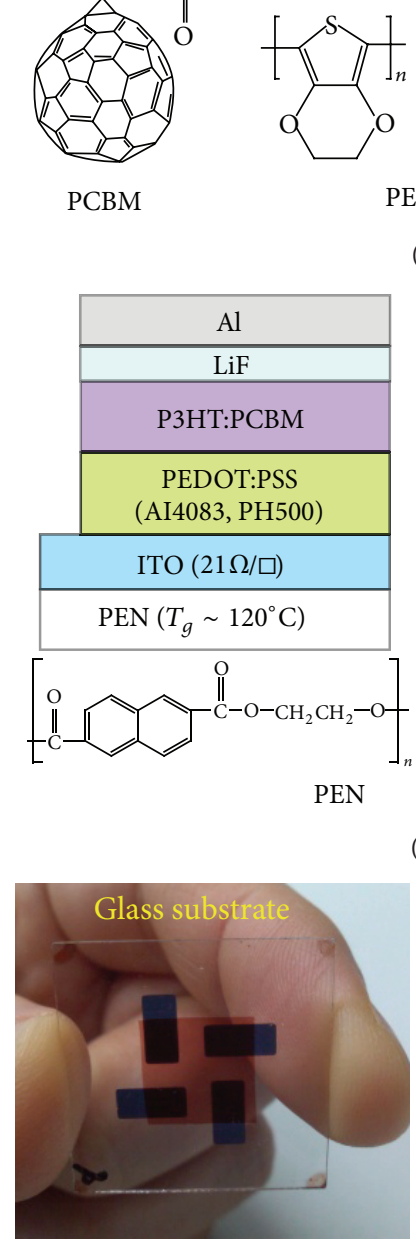

PEDOT:PSS

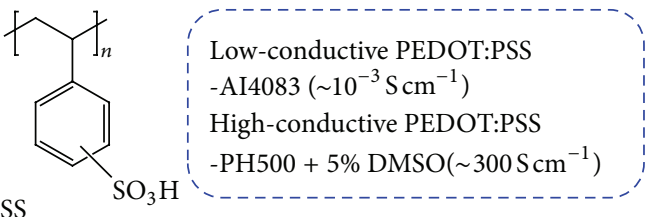

(a)
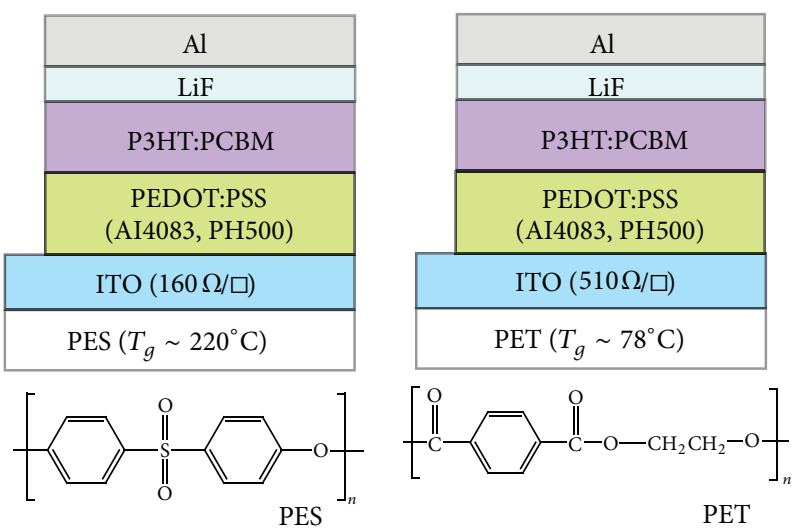

(b)

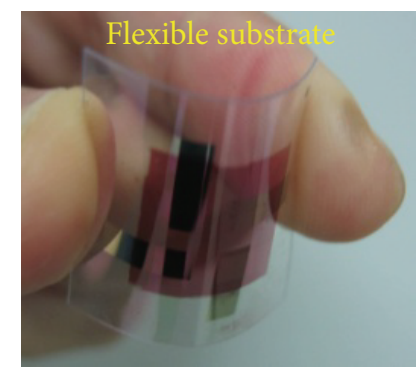

(c)

FIGURE 1: (a) Chemical structure of materials used in this work, (b) device structures with four different ITO substrates (glass and flexible plastics) and two different buffer layers (AI4083 and PH500) (note the chemical structures of plastic substrates), and (c) photographs of OPV devices fabricated using glass (left) and flexible plastic (right) substrates.

between $550 \mathrm{~nm}$ and $650 \mathrm{~nm}$ for the PEN and PET substrates (note that the P3HT absorption ends at around $650 \mathrm{~nm}$ ). Interestingly, the PES substrate exhibited a sensitive transmittance response with the wavelength, which is different from other substrates.

The current density-voltage $(J-V)$ characteristics of OPV devices under illumination of the simulated solar light $\left(\mathrm{AM} 1.5,100 \mathrm{~mW} / \mathrm{cm}^{2}\right)$ are shown in Figure 3. All devices show similar open-circuit voltage $\left(V_{\mathrm{OC}}\right)$ of about $0.6 \mathrm{~V}$, suggesting good contact between the active layer and the buffer layers. For the devices using AI4083, their $J_{\mathrm{SC}}, \mathrm{FF}$, and PCE are, however, significantly decreased, from $6.2 \mathrm{~mA} / \mathrm{cm}^{2}$, 0.605 , and $2.3 \%$ in the glass $/$ ITO device to $0.5 \mathrm{~mA} / \mathrm{cm}^{2}, 0.139$, and $0.04 \%$ in the PET/ITO device, respectively. We note that the relatively low PCE of $2.3 \%$ in the glass/ITO device was due to the low postannealing temperature at $120^{\circ} \mathrm{C}$ after device fabrication, as mentioned in the Experimental section (our normal device has a PCE of over 3\% after postannealing treatment at $140 \sim 150^{\circ} \mathrm{C}$, as reported previously $\left.[20,21]\right)$.
Based on the $J-V$ characteristics, we tried to analyze the main factor to decrease the PCE with increasing substrate $R_{\text {sheet }}$. The efficiency of an OPV is typically influenced by the following relation [22]:

$$
\eta=\eta_{a} \times \eta_{g} \times \eta_{\text {diff }} \times \eta_{\text {dis }} \times \eta_{\mathrm{tr}} \times \eta_{c}
$$

where $\eta_{a}$ is the photon absorption efficiency, $\eta_{g}$ is the generation efficiency of excitons, $\eta_{\text {diff }}$ is the exciton diffusion efficiency, $\eta_{\text {dis }}$ is the efficiency of hole-electron separation (exciton dissociation), $\eta_{\mathrm{tr}}$ is the efficiency of carrier transport in the active layer towards the electrodes, and $\eta_{c}$ is the charge collection efficiency at the respective electrodes. We can assume that each device has equal capacity of $\eta_{g}, \eta_{\text {diff, }}$, $\eta_{\text {dis }}$, and $\eta_{\text {tr }}$, because their device structure including active (P3HT:PCBM) and buffer (AI4083) layers is exactly the same. $\eta_{a}$ and $\eta_{c}$ then remain as responsible factors. From Figure 1, the average optical transmittance of the ITO substrates at the wavelength of $400-700 \mathrm{~nm}$ is above $70 \%$. The difference in transmittance among the ITO substrates, which is directly 


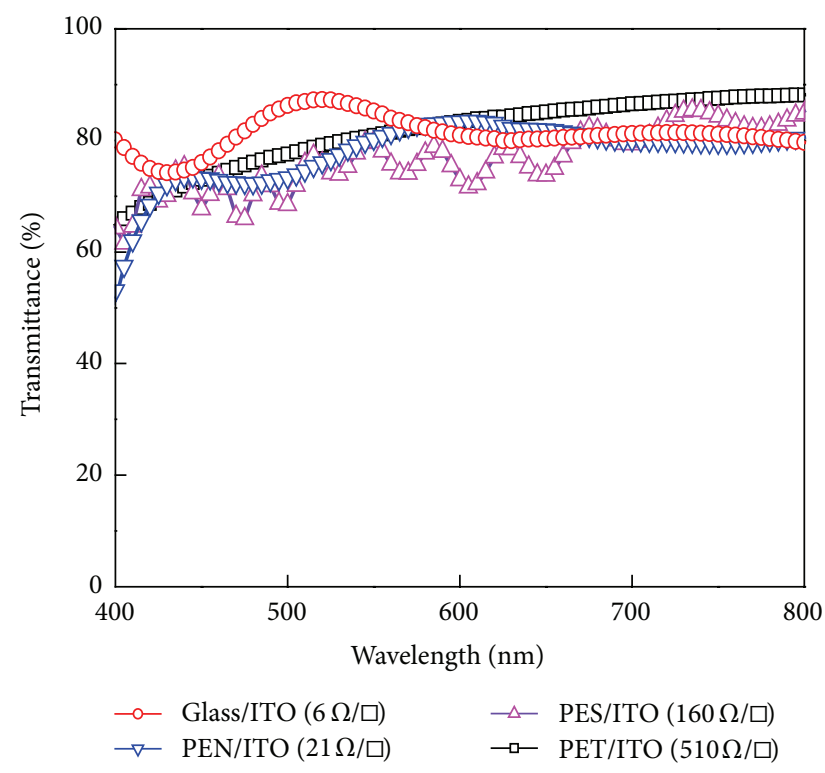

Figure 2: Optical transmittance of four different ITO substrates used in this work. The sheet resistance of each substrate is given in the legend.

related to $\eta_{a}$, is within $20 \%$, while their $R_{\text {sheet }}$ difference is almost two orders. Thus, the decreasing photovoltaic performance with increasing $R_{\text {sheet }}$ of the substrate is not significantly related to the transmittance of the base substrate, but rather to the high $R_{\text {sheet }}$ of the ITO electrode. This reflects that the main factor of limitation is the hole collection efficiency at the hole-collecting electrode $\left(\eta_{c}\right)$, not the light absorption difference $\left(\eta_{a}\right)$. Hence we tried to correlate the device performances with the conductivity of each substrate which can represent the hole collection efficiency in Figure 4.

Figure 4 presents the $V_{\mathrm{OC}}, J_{\mathrm{SC}}, \mathrm{FF}, \mathrm{PCE}$, and $R_{S}$ changes as a function of $R_{\text {sheet }}$ (ITO) of the substrates under illumination of AM1.5, which clearly shows the relations between these parameters. The $V_{\mathrm{OC}}$ is almost independent of $R_{\text {sheet }}$ of ITO, as mentioned before. However, the $J_{\mathrm{SC}}$ and FF values gradually decreased with increasing $R_{\text {sheet }}$ of the ITO, resulting in a decrease of the PCE. Moreover, the decreasing trend in $J_{\mathrm{SC}}, \mathrm{FF}$, and PCE is closely connected with the increase of $R_{S}$ of the devices. The hole collection efficiency at the anode $\left(\eta_{c}\right)$ is usually affected by $R_{S}$, which is also the dominant parameter determining the FF by altering the slope of the $J$ $V$ curve near the $V_{\text {OC }}$ and is a key factor for high-efficiency solar cells [22-25]. $R_{S}$ represents the total resistance of the cell and depends on the resistivity of the organic material(s), the metal electrodes, and the metal/organic interface [24]. As all devices were fabricated with the same structure and active materials under an identical process, it is reasonable to assume that the resistances of PEDOT:PSS, P3HT:PCBM, and $\mathrm{LiF} / \mathrm{Al}$ remained constant among devices. Therefore, $R_{S}$ is mainly changed with $R_{\text {sheet }}$ of the ITO anode in our case. Xue et al. reported that the contribution of $R_{\text {sheet }}$ of the ITO electrode to the $R_{S}$ of an OPV is more critical in the fabrication of the OPV for a large area of more than $0.01 \mathrm{~cm}^{2}$

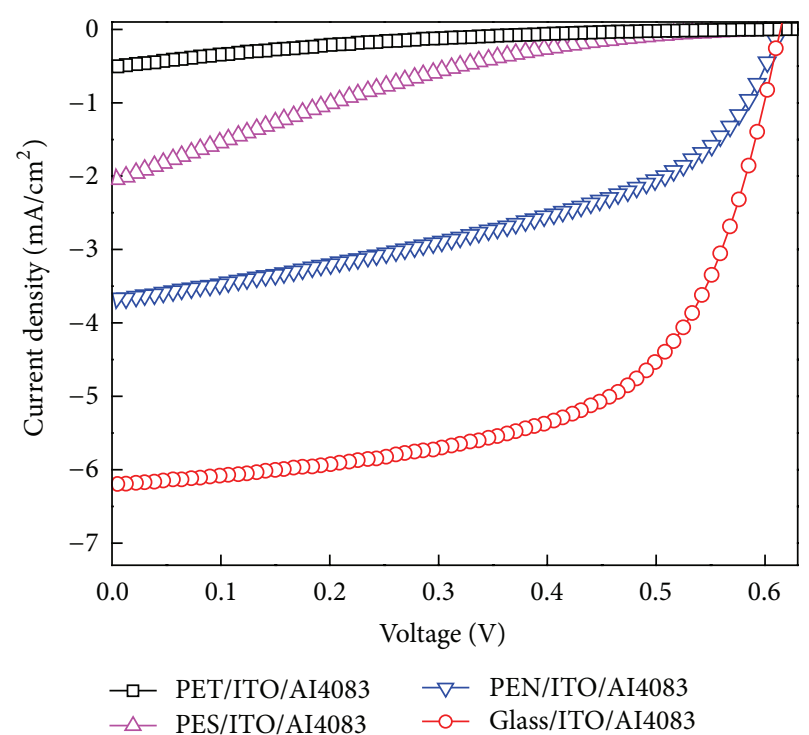

(a)

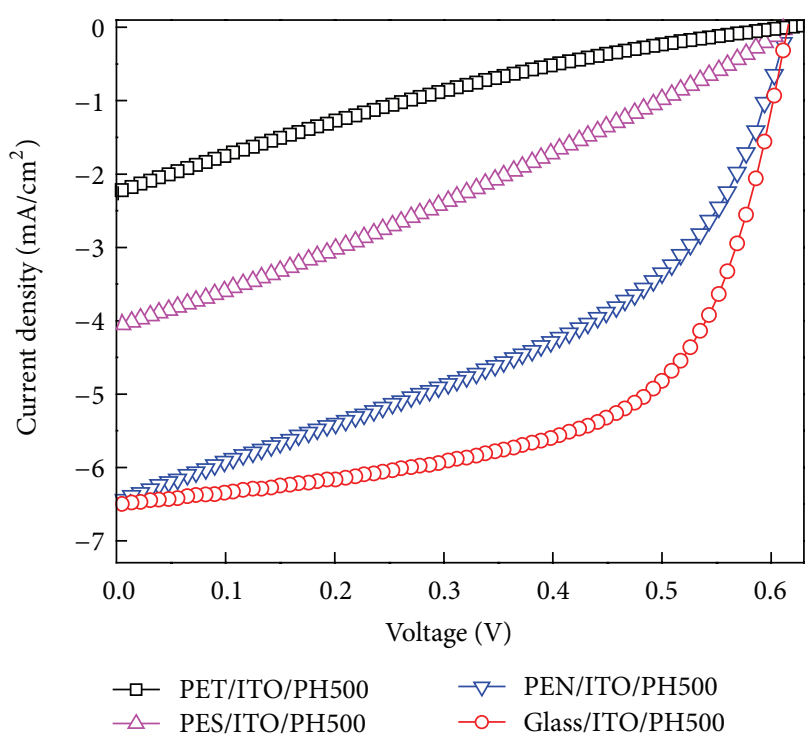

(b)

FIgure 3: Current density-voltage $(J-V)$ characteristics of OPV devices fabricated using four different ITO substrates and holecollecting buffer layers (PEDOT:PSS: (a) AI4083 and (b) PH500). All measurements were performed under illumination of simulated solar light (AM1.5, $\left.100 \mathrm{~mW} / \mathrm{cm}^{2}\right)$.

[26]. Several other reports have described the effect of $R_{\text {sheet }}$ on the $R_{S}$ and the cell design rule to minimize the $R_{S}$ in large area devices [27-31].

As additional indirect evidence for poor hole extraction (collection) due to the high-resistivity ITO, we can see a kink (or S-curve) characteristic in devices with high $R_{S}$ such as PET/ITO/AI4083 and PES/ITO/AI4083. This kink causes a negative curvature that can substantially reduce the FF, and therefore the solar cell performance. The kink of the $J-V$ curve under illumination was due to several reasons, such as large interfacial energy gaps at the electrode-active layer 


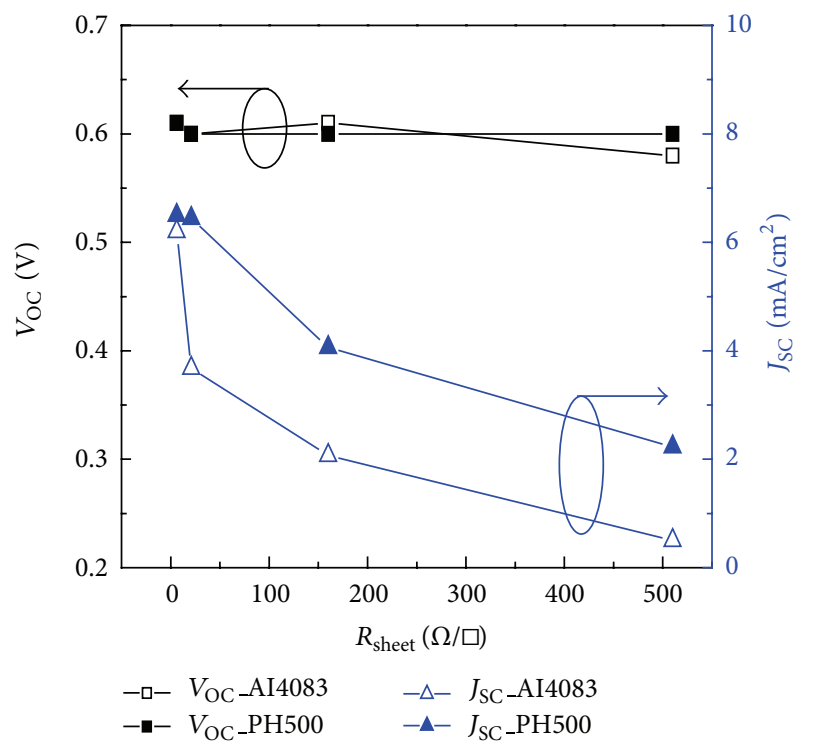

(a)

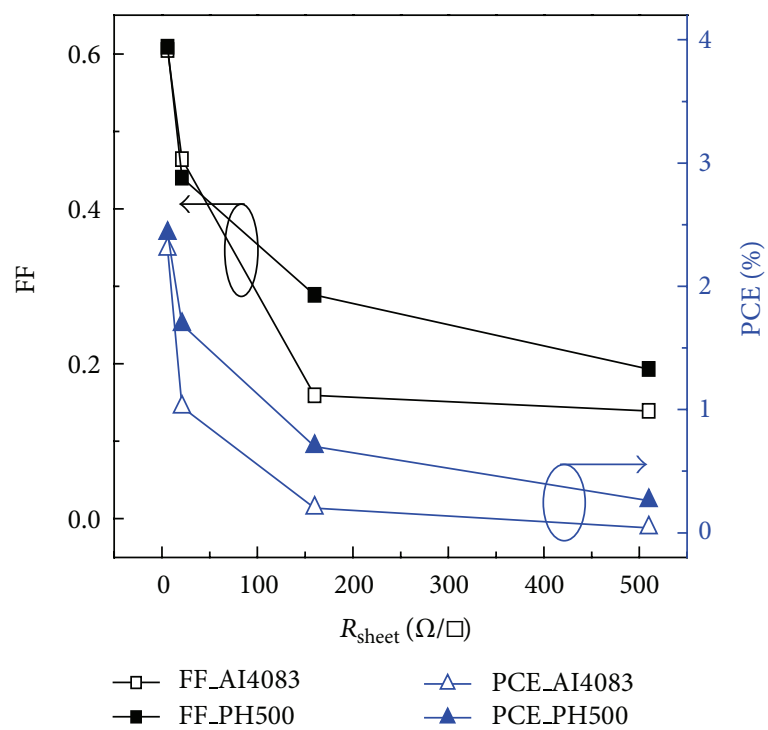

(b)

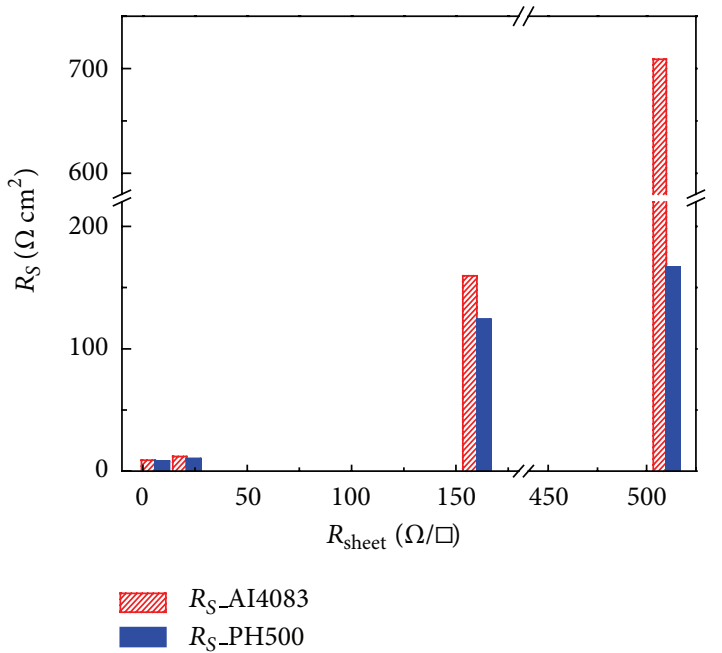

(c)

Figure 4: (a) Open-circuit voltage $\left(V_{\mathrm{OC}}\right)$ and short-circuit current density $\left(J_{\mathrm{SC}}\right)$, (b) FF and PCE, and (c) series resistance $\left(R_{\mathrm{S}}\right)$ as a function of the sheet resistance $\left(R_{\text {sheet }}\right)$ of the ITO electrode on the substrates.

interface, unbalanced mobility between holes and electrons $[32,33]$, nonuniform contact or incomplete coverage of the metal over the active layer [34, 35], slow charge transfer at one of the electrical contacts of the active layer [36], strong interfacial dipoles, defects, and traps that can create barriers for charge extraction [37], and defect-induced nonefficient extraction of charge leading to buildup of a counter field $[38,39]$. These can be summarized that the kink characteristic is caused by a counterfield created by accumulated space charges from unbalanced charge carrier extraction. In devices incorporating our high-resistivity ITO substrate, we may reasonably suppose that separated holes undergo restricted extraction at the anode and show a kink $J-V$ curve.

Next, we checked whether these losses that originate from the high $R_{\text {sheet }}$ ITO can be reduced by using a highconductivity buffer layer. The conductivity of PEDOT:PSS can be increased by up to two or three orders of magnitude by adding high-boiling point and/or polar compounds such as diethylene glycol (DEG), ethylene glycol (EG), dimethylsulfoxide (DMSO), sorbitol, and glycerol, due to the phase separation of each PEDOT-rich region and PSS-rich region, as reported in previous works [40-42]. We used PH500 doped with 5\% DMSO (in this report, we call it PH500) to improve the conductivity up to $500 \Omega / \square$. From Figures 3 and 4 , the $J_{\mathrm{SC}}, \mathrm{FF}$, and PCE were greatly improved by using a highconductivity PH500 buffer layer. Typically, the effect of highconductivity PH500 is more pronounced with the high $R_{\text {sheet }}$ of the ITO electrode. As a result, PCE and $R_{S}$ are, respectively, improved by a factor of 3.5 and 1.29 for PES/ITO and 6.5 and 4.25 for PET/ITO (see Table 1). This indicates that the poor conductivity of the ITO electrode can be partly compensated by a high-conductivity buffer layer via the reduction of $R_{S}$. 
TABLE 1: Summary of device parameters for organic photovoltaic devices with four different ITO substrates (glass and flexible plastics) and two different buffer layers (AI4083 and PH500).

\begin{tabular}{|c|c|c|c|c|c|c|c|c|c|c|c|}
\hline Substrate & PEDOT: PSS & \multicolumn{2}{|c|}{$V_{\mathrm{OC}}(\mathrm{V})$} & \multicolumn{2}{|c|}{$J_{\mathrm{SC}}\left(\mathrm{mA} / \mathrm{cm}^{2}\right)$} & \multicolumn{2}{|c|}{ FF } & \multicolumn{2}{|c|}{ PCE (\%) } & \multicolumn{2}{|c|}{$R_{S}\left(\Omega \mathrm{cm}^{2}\right)^{\mathrm{a}}$} \\
\hline Glass/ITO & $\begin{array}{l}\text { AI4083 } \\
\text { PH500 }\end{array}$ & $\begin{array}{l}0.61 \\
0.61\end{array}$ & $(1.00)^{\mathrm{b}}$ & $\begin{array}{l}6.20 \\
6.50\end{array}$ & $(1.05)^{\mathrm{b}}$ & $\begin{array}{l}0.605 \\
0.609\end{array}$ & $(1.01)^{\mathrm{b}}$ & $\begin{array}{l}2.30 \\
2.43\end{array}$ & $(1.06)^{\mathrm{b}}$ & $\begin{array}{l}9.0 \\
8.1\end{array}$ & $(1.11)^{\mathrm{b}}$ \\
\hline PEN/ITO & $\begin{array}{l}\text { AI4083 } \\
\text { PH500 }\end{array}$ & $\begin{array}{l}0.60 \\
0.60\end{array}$ & $(1.00)^{\mathrm{b}}$ & $\begin{array}{l}3.68 \\
6.44\end{array}$ & $(1.75)^{\mathrm{b}}$ & $\begin{array}{l}0.464 \\
0.440\end{array}$ & $(0.95)^{\mathrm{b}}$ & $\begin{array}{l}1.02 \\
1.69\end{array}$ & $(1.66)^{\mathrm{b}}$ & $\begin{array}{l}12.0 \\
10.1\end{array}$ & $(1.19)^{\mathrm{b}}$ \\
\hline PES/ITO & $\begin{array}{l}\text { AI4083 } \\
\text { PH500 }\end{array}$ & $\begin{array}{l}0.61 \\
0.60\end{array}$ & $(0.98)^{b}$ & $\begin{array}{l}2.07 \\
4.06\end{array}$ & $(1.96)^{b}$ & $\begin{array}{l}0.159 \\
0.289\end{array}$ & $(1.82)^{b}$ & $\begin{array}{l}0.20 \\
0.70\end{array}$ & $(3.50)^{\mathrm{b}}$ & $\begin{array}{l}159.7 \\
123.9\end{array}$ & $(1.29)^{\mathrm{b}}$ \\
\hline PET/ITO & $\begin{array}{l}\text { AI4083 } \\
\text { PH500 }\end{array}$ & $\begin{array}{l}0.58 \\
0.60\end{array}$ & $(1.03)^{\mathrm{b}}$ & $\begin{array}{l}0.50 \\
2.23\end{array}$ & $(4.46)^{\mathrm{b}}$ & $\begin{array}{l}0.139 \\
0.193\end{array}$ & $(1.39)^{\mathrm{b}}$ & $\begin{array}{l}0.04 \\
0.26\end{array}$ & $(6.50)^{\mathrm{b}}$ & $\begin{array}{l}708.8 \\
166.8\end{array}$ & $(4.25)^{\mathrm{b}}$ \\
\hline Glass/PH & (ITO-free) & 0.61 & & 3.98 & & 0.364 & & 0.88 & & 90.5 & \\
\hline
\end{tabular}

${ }^{\mathrm{a}} R_{S}$ is calculated from the inverse slope of $J-V$ curve at high cell voltages $(J=0) .{ }^{\mathrm{b}}$ The numbers in parentheses denote the ratio of PH500 to AI4083 (for $V_{\mathrm{OC}}$, $J_{S C}, F F$, and PCE) or the ratio of AI4083 to PH500 (for $R_{S}$ ).

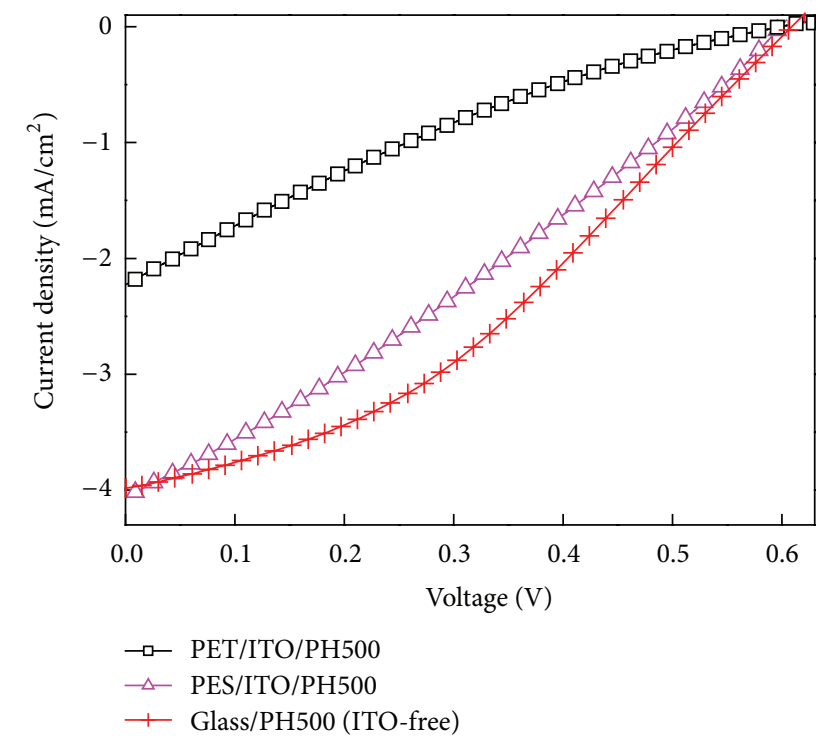

FIgURE 5: $J-V$ characteristics of the ITO-free OPV device (glass/ PEDOT:PSS(PH500)/P3HT:PCBM/LiF/Al), the PET/ITO-based flexible plastic device (PET/ITO/PEDOT:PSS(PH500)/P3HT: $\mathrm{PCBM} / \mathrm{LiF} / \mathrm{Al}$ ), and the PES/ITO-based flexible plastic device (PES/ITO/PEDOT:PSS(PH500)/P3HT:PCBM/LiF/Al).

Finally, we can suppose that an ITO electrode with similar or higher resistance than the buffer layer is not as helpful as an ITO-free case to extract hole carriers, because interfacial resistance at inorganic ITO/organic PEDOT:PSS inevitably arises. From this assumption, we fabricated an ITO-free device using PH500 (spin-coating at $2500 \mathrm{rpm}$, $30 \mathrm{~nm}, 500 \Omega / \square$ ) as an anode.

Figure 5 and Table 1 show that the ITO-free device has not only equivalent or higher $J_{S C}$ but also a high FF with an improved kink curve compared with devices made on PET/ITO or PES/ITO. This indicates that the interface property between ITO and PEDOT:PSS is also another important consideration when developing high-efficiency large-area OPVs, as discussed in many reports [16, 17, 24].

\section{Conclusions}

Eight different OPV devices using four different types of ITO substrates have been fabricated to investigate the influence of the hole-collecting electrode (ITO) and buffer layers (PEDOT:PSS). The optical transmittance of flexible plastic substrates was slightly lower than that of the glass substrate. The $J-V$ curve shape became worse as the ITO conductivity of substrates increased irrespective of the kind of PEDOT:PSS, indicating significant effect of the $R_{\text {sheet }}$ of the ITO electrode in different substrates on the performance of OPV devices. However, the high-conductivity buffer layer (PH500) resulted in better device performances than the low-conductivity buffer layer (AI4083), which supports that the conductivity of hole-collecting buffer layer can compensate for the increase of $R_{S}$ in OPV devices with a high $R_{\text {sheet }}$ ITO electrode. The present result showed that the high conductivities of holecollecting electrode (ITO) and buffer layer (PEDOT:PSS) are together beneficial to realize an efficient OPV devices by increasing the FF as well as the $J_{\mathrm{SC}}$ through reduction of the $R_{S}$ of devices. Therefore, new transparent electrode and buffer layer materials with high conductivity should be key technological components for successful commercialization of OPV modules.

\section{Acknowledgments}

This work was supported by the DGIST R\&D Program of the Ministry of Education, Science, and Technology of Republic of Korea (12-EN-02) and National Research Foundation Grant (2012-000523).

\section{References}

[1] G. Dennler, M. C. Scharber, and C. J. Brabec, "Polymer-fullerene bulk-heterojunction solar cells," Advanced Materials, vol. 21, no. 13, pp. 1323-1338, 2009.

[2] B. C. Thompson and J. M. J. Fréchet, "Polymer-fullerene composite solar cells," Angewandte Chemie, vol. 47, no. 1, pp. 5877, 2008. 
[3] Y. Kim, S. Cook, S. M. Tuladhar et al., "A strong regioregularity effect in self-organizing conjugated polymer films and highefficiency polythiophene:fullerene solar cells," Nature Materials, vol. 5, no. 3, pp. 197-203, 2006.

[4] J. Y. Kim, S. H. Kim, H. Lee et al., "New architecture for high-efficiency polymer photovoltaic cells using solution-based titanium oxide as an optical spacer," Advanced Materials, vol. 18, no. 5, pp. 572-576, 2006.

[5] M. D. Irwin, D. B. Buchholz, A. W. Hains, R. P. H. Chang, and T. J. Marks, " $p$-type semiconducting nickel oxide as an efficiency-enhancing anode interfacial layer in polymer bulkheterojunction solar cells," Proceedings of the National Academy of Sciences of the United States of America, vol. 105, no. 8, pp. 2783-2787, 2008.

[6] M. C. Scharber, D. Mühlbacher, M. Koppe et al., "Design rules for donors in bulk-heterojunction solar cells-towards $10 \%$ energy-conversion efficiency," Advanced Materials, vol. 18, no. 6, pp. 789-794, 2006.

[7] G. Dennler, M. C. Scharber, T. Ameri et al., "Design rules for donors in bulk-heterojunction tandem solar cells-towards 15\% energy-conversion efficiency," Advanced Materials, vol. 20, no. 3, pp. 579-583, 2008.

[8] W. A. MacDonald, "Flexible substrates requirements for organic photovoltaics," in Organic Photovoltaics: Materials, Device Physics, and ManufacturIng Technologies, C. Brabec, V. Dyakonov, and U. Scherf, Eds., chapter 17, pp. 471-489, WileyVCH, Weinheim, Germany, 2008.

[9] J. Kang, S. Lee, D. Kim et al., "Reduction of series resistance in organic photovoltaic using low sheet resistance of ITO electrode," Electrochemical and Solid-State Letters, vol. 12, no. 3, pp. H64-H66, 2009.

[10] A. Elschner and S. Kirchmeyer, "PEDOT-type materials in organic solar cells," in Organic Photovoltaics: Materials, Device Physics, and ManufacturIng Technologies, C. Brabec, V. Dyakonov, and U. Scherf, Eds., chapter 7, pp. 213-242, WileyVCH, Weinheim, Germany, 2008.

[11] http://www.clevios.com/en/downloads/heraeus-conductivepolymers-downloads.aspx.

[12] C. Ko, Y. Lin, F. Chen, and C. Chu, "Modified buffer layers for polymer photovoltaic devices," Applied Physics Letters, vol. 90, no. 6, Article ID 063509, 2007.

[13] Z. Hu, J. Zhang, Z. Hao, and Y. Zhao, "Influence of doped PEDOT:PSS on the performance of polymer solar cells," Solar Energy Materials and Solar Cells, vol. 95, no. 10, pp. 2763-2767, 2011.

[14] T. Xiao, W. Cui, J. Anderegg, J. Shinar, and R. Shinar, "Simple routes for improving polythiophene: fullerene-based organic solar cells," Organic Electronics: Physics, Materials, Applications, vol. 12, no. 2, pp. 257-262, 2011.

[15] K. Sun, Y. Xia, and J. Ouyang, "Improvement in the photovoltaic efficiency of polymer solar cells by treating the poly $(3,4-$ ethylenedioxythiophene): poly(styrenesulfonate) buffer layer with co-solvents of hydrophilic organic solvents and hydrophobic 1,2-dichlorobenzene," Solar Energy Materials and Solar Cells, vol. 97, pp. 89-96, 2012.

[16] G. Kim, H. Song, and J. Y. Kim, "The effect of introducing a buffer layer to polymer solar cells on cell efficiency," Solar Energy Materials and Solar Cells, vol. 95, no. 4, pp. 1119-1122, 2011.

[17] C. Gong, H. B. Yang, Q. L. Song, Z. S. Lu, and C. M. Li, "Mechanism for dimethylformamide-treatment of poly(3,4ethylenedioxythiophene): poly(styrene sulfonate) layer to enhance short circuit current of polymer solar cells," Solar Energy Materials and Solar Cells, vol. 100, pp. 115-119, 2012.

[18] P. G. Karagiannidis, N. Kalfagiannis, D. Georgiou et al., "Effects of buffer layer properties and annealing process on bulk heterojunction morphology and organic solar cell performance," Journal of Materials Chemistry, vol. 22, no. 29, pp. 14624-14632, 2012.

[19] D. K. Schroder, Semiconductor Material and Device Characterization, pp. 1-60, chapter 1, John Wiley \& Sons, Tempe, Ariz, USA, 2006.

[20] S. Jeong, Y. Kwon, B. Choi, H. Ade, and Y. S. Han, "Improved efficiency of bulk heterojunction poly(3-hexylthiophene):[6,6]phenyl- $\mathrm{C}_{61}$-butyric acid methyl ester photovoltaic devices using discotic liquid crystal additives," Applied Physics Letters, vol. 96, no. 18, Article ID 183305, 3 pages, 2010.

[21] S. Jeong, S. Woo, H. Lyu, and Y. S. Han, "Effects of a perfluorinated compound as an additive on the power conversion efficiencies of polymer solar cells," Solar Energy Materials and Solar Cells, vol. 95, no. 7, pp. 1908-1914, 2011.

[22] A. Moliton and J. Nunzi, "How to model the behaviour of organic photovoltaic cells," Polymer International, vol. 55, no. 6, pp. 583-600, 2006.

[23] Y. Huang, S. Dai, S. Chen et al., "Theoretical modeling of the series resistance effect on dye-sensitized solar cell performance," Applied Physics Letters, vol. 95, no. 24, Article ID 243503, 2009.

[24] J. D. Servaites, M. A. Ratner, and T. J. Marks, "Organic solar cells: a new look at traditional models," Energy and Environmental Science, vol. 4, no. 11, pp. 4410-4422, 2011.

[25] M. Kim, B. Kim, and J. Kim, "Effective variables to control the fill factor of organic photovoltaic cells," ACS Applied Materials and Interfaces, vol. 1, no. 6, pp. 1264-1269, 2009.

[26] J. Xue, S. Uchida, B. P. Rand, and S. R. Forrest, " $4.2 \%$ efficient organic photovoltaic cells with low series resistances," Applied Physics Letters, vol. 84, no. 16, pp. 3013-3015, 2004.

[27] B. Muhsin, J. Renz, K. Drüe, G. Gobsch, and H. Hoppe, "Influence of polymer solar cell geometry on series resistance and device efficiency," Physica Status Solidi A, vol. 206, no. 12, pp. 2771-2774, 2009.

[28] M. W. Denhoff and N. Drolet, "The effect of the front contact sheet resistance on solar cell performance," Solar Energy Materials and Solar Cells, vol. 93, no. 9, pp. 1499-1506, 2009.

[29] S. Park, W. Jeong, D. Kim et al., "Large-area organic solar cells with metal subelectrode on indium tin oxide anode," Applied Physics Letters, vol. 96, no. 17, Article ID 173301, 2010.

[30] G. T. Koishiyev and J. R. Sites, "Impact of sheet resistance on 2D modeling of thin-film solar cells," Solar Energy Materials and Solar Cells, vol. 93, no. 3, pp. 350-354, 2009.

[31] W. Jeong, J. Lee, S. Park, J. Kang, and J. Kim, "Reduction of collection efficiency of charge carriers with increasing cell size in polymer bulk heterojunction solar cells," Advanced Functional Materials, vol. 21, no. 2, pp. 343-347, 2011.

[32] J. Nelson, J. Kirkpatrick, and P. Ravirajan, "Factors limiting the efficiency of molecular photovoltaic devices," Physical Review B, vol. 69, no. 3, Article ID 035337, 11 pages, 2004.

[33] Y. Kim, A. M. Ballantyne, J. Nelson, and D. D. C. Bradley, "Effects of thickness and thermal annealing of the PEDOT:PSS layer on the performance of polymer solar cells," Organic Electronics: Physics, Materials, Applications, vol. 10, no. 1, pp. 205-209, 2009.

[34] D. Gupta, M. Bag, and K. S. Narayan, "Correlating reduced fill factor in polymer solar cells to contact effects," Applied Physics Letters, vol. 92, no. 9, Article ID 093301, 2008. 
[35] D. Gupta, S. Mukhopadhyay, and K. S. Narayan, "Fill factor in organic solar cells," Solar Energy Materials and Solar Cells, vol. 94, no. 8, pp. 1309-1313, 2010.

[36] M. Glatthaar, M. Riede, N. Keegan et al., "Efficiency limiting factors of organic bulk heterojunction solar cells identified by electrical impedance spectroscopy," Solar Energy Materials and Solar Cells, vol. 91, no. 5, pp. 390-393, 2007.

[37] A. Kumar, S. Sista, and Y. Yang, "Dipole induced anomalous S-shape I-V curves in polymer solar cells," Journal of Applied Physics, vol. 105, no. 9, Article ID 094512, 2009.

[38] J. Meiss, M. K. Riede, and K. Leo, “Optimizing the morphology of metal multilayer films for indium tin oxide (ITO)-free inverted organic solar cells," Journal of Applied Physics, vol. 105, no. 6, Article ID 063108, 2009.

[39] J. Meiss, M. K. Riede, and K. Leo, “Towards efficient tin-doped indium oxide (ITO)-free inverted organic solar cells using metal cathodes," Applied Physics Letters, vol. 94, no. 1, Article ID 013303, 2009.

[40] A. M. Nardes, R. A. J. Janssen, and M. Kemerink, "A morphological model for the solvent-enhanced conductivity of PEDOT:PSS thin films," Advanced Functional Materials, vol. 18, no. 6, pp. 865-871, 2008.

[41] J. Hwang, F. Amy, and A. Kahn, "Spectroscopic study on sputtered PEDOT.PSS: role of surface PSS layer," Organic Electronics: Physics, Materials, Applications, vol. 7, no. 5, pp. 387396, 2006.

[42] S. Na, G. Wang, S. Kim et al., "Evolution of nanomorphology and anisotropic conductivity in solvent-modified PEDOT:PSS films for polymeric anodes of polymer solar cells," Journal of Materials Chemistry, vol. 19, no. 47, pp. 9045-9053, 2009. 

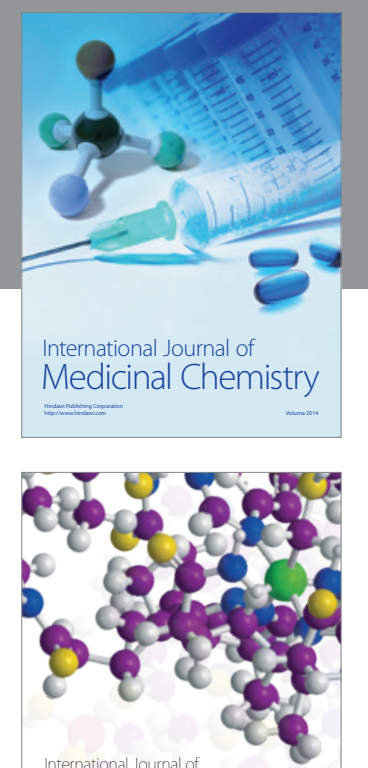

\section{Carbohydrate} Chemistry

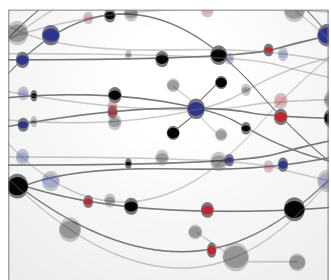

The Scientific World Journal
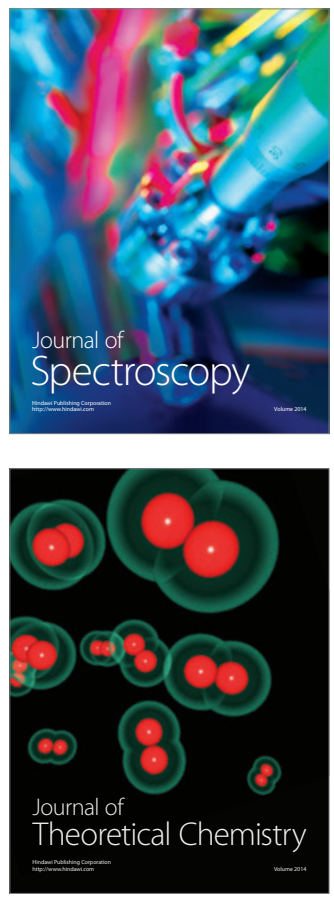
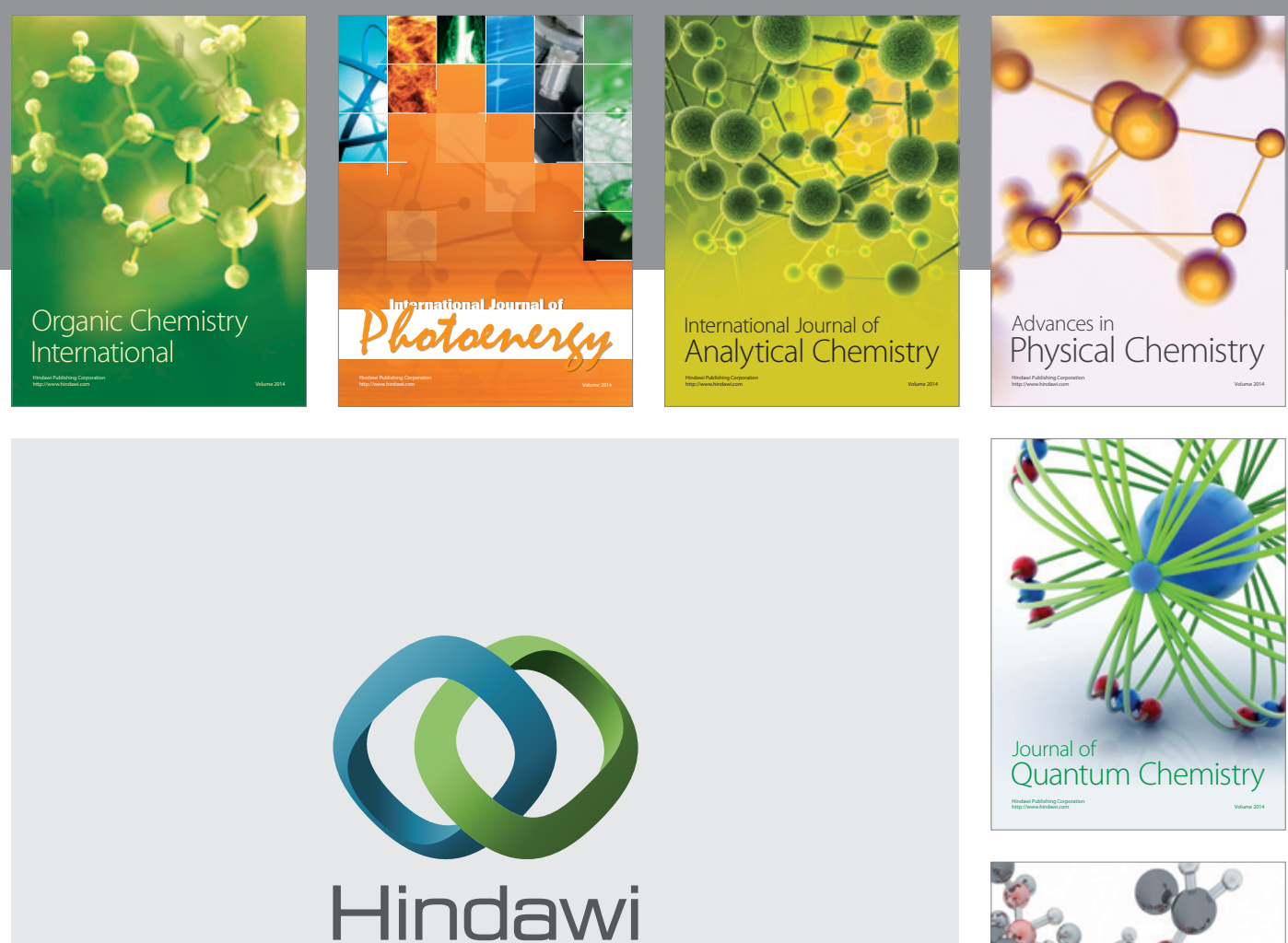

Submit your manuscripts at

http://www.hindawi.com

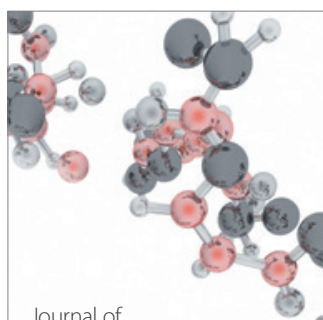

Analytical Methods

in Chemistry

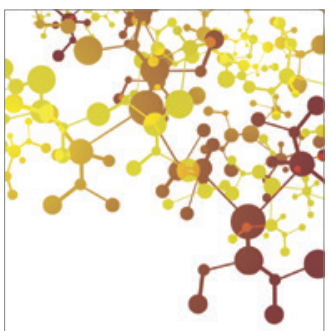

Journal of

Applied Chemistry

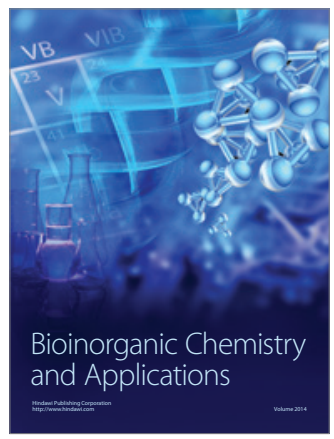

Inorganic Chemistry
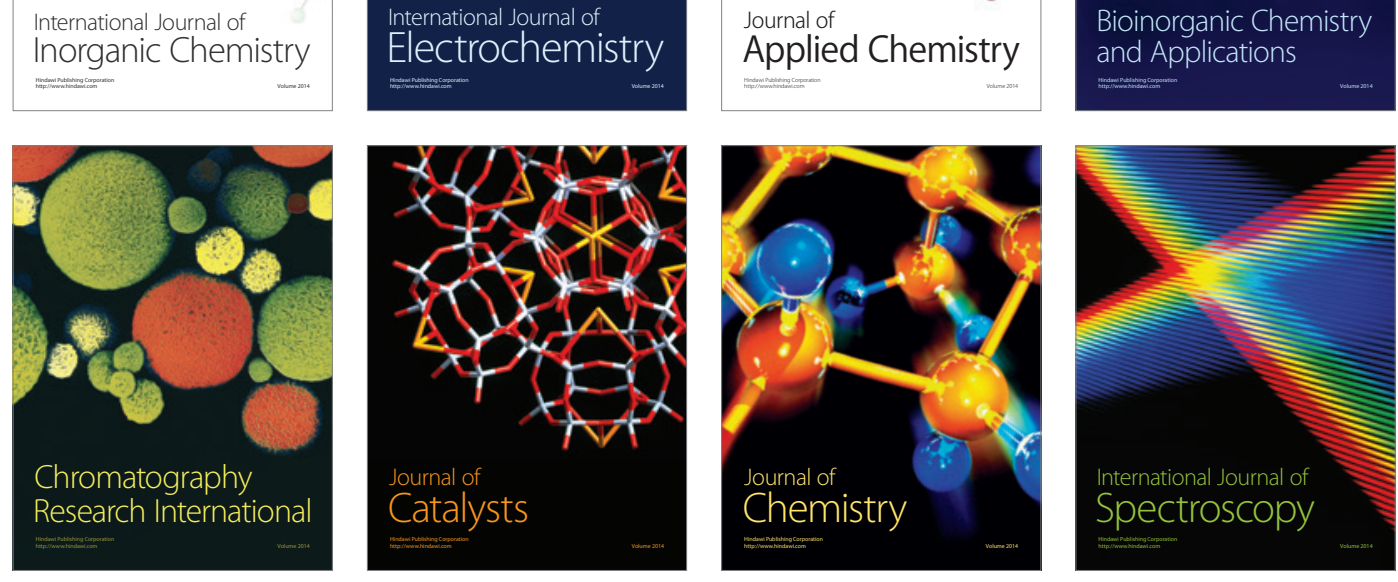